\title{
Multi-scale toughening of fibre composites using carbon nanofibres and z-pins
}

Raj B. Ladani ${ }^{\mathrm{a}}$, Anil R. Ravindran ${ }^{\mathrm{a}}$, Shuying $\mathrm{Wu}^{\mathrm{a}}$, Khomkrit Pingkarawat ${ }^{\mathrm{a}}$, Anthony J. Kinloch ${ }^{\mathrm{b}}$, Adrian P. Mouritz ${ }^{\mathrm{a}}$, Robert O Ritchie ${ }^{\mathrm{c}}$, and Chun H. Wang ${ }^{\mathrm{a} *}$,

${ }^{\text {a} S i r ~ L a w r e n c e ~ W a c k e t t ~ A e r o s p a c e ~ R e s e a r c h ~ C e n t r e, ~ S c h o o l ~ o f ~ E n g i n e e r i n g, ~ R M I T ~ U n i v e r s i t y, ~ G P O ~ B o x ~}$ 2476, Melbourne, VIC 3001, Australia.

${ }^{\mathrm{b}}$ Department of Mechanical Engineering, Imperial College London, South Kensington Campus, London SW7 2AZ, U.K.

${ }^{\mathrm{c}}$ Materials Sciences Division, Lawrence Berkeley National Laboratory, and Department of Materials Science and Engineering, University of California, Berkeley, CA 94720, USA

\section{Abstract}

Improving the interlaminar fracture toughness of fibre-reinforced composites based on thermosetting polymeric matrices is of significant interest to a broad range of applications. In the present work we report a multi-scale approach to synergistically toughen composites by combining nano- and macro-scale reinforcements inspired by natural composite materials. Carbon reinforcements with two different length scales are used: nano-scale carbon nanofibres ( 100 nm diameter) and macro-scale carbon z-pins ( 280 $\mu \mathrm{m}$ diameter) to reinforce continuous carbon-fibre composites in the through-thickness direction. The resultant composite, featuring three-dimensional reinforcement architecture, possesses triple toughening mechanisms at three different scales, thus yielding a synergistic effect. At the nano-scale, the carbon nanofibres alone promote high mode I delamination resistance ( $70 \%$ increase in interlaminar fracture energy) by multiple intrinsic and extrinsic toughening processes around the crack tip. The macro-size carbon z-pins, together with the crossover continuous fibres, promote a strong extrinsic toughening mechanism ( 200\% increase in the interlaminar fracture energy) behind the crack tip and over a larger length-scale via both the z-pins and crossover fibres bridging the crack faces. When used concurrently, the nanofillers and z-pins promote a higher toughness under quasi-static loading ( $400 \%$ increase in fracture energy) than when used separately due to a multiplicative effect from the interplay between intrinsic and extrinsic toughening processes operative ahead of, and behind, the crack tip. Under mode I interlaminar cyclic-fatigue loading, the multiscale laminates show a strong improvement in resistance against fatigue delamination growth. Similar to the synergistic increase in fracture energy, a greater increase in the delamination fatigue resistance occurs when both are active together. However, the results indicate that the synergistic effect of the multi-scale toughening is statistically significant under quasi-static loading but not under fatigue loading. A very small reduction $(\sim 2 \%)$ in the tensile strength is observed for the multi-scale reinforced laminates.

Keywords: B. Synergism; B. Delamination; B. Fatigue; C. Fibre bridging; Bioinspired composite 


\section{Introduction}

2 Fibre-reinforced composite materials are widely used in many engineering applications due to their

3 lightweight design with excellent in-plane properties and resistance to fatigue and environmental

4 degradation. However, in the absence of through-thickness reinforcement, thermosetting polymer based 5 composites have low interlaminar and intralaminar fracture toughness, making them susceptible to matrix6 dominated cracking [1, 2]. Many techniques have been developed to address these drawbacks by, for 7 example, inserting out-of-plane fibers through mechanical punching [3], stitching [4], 3D weaving [5], 8 nanofiller inclusion in the matrix [6] and at ply interfaces [7, 8], and interleaving toughening layers at ply 3D stitched, woven and z-pinned composites is the uncertainty concerning the degree to which throughthickness reinforcement degrades composites' in-plane properties [10,11]. For instance, a common defect in z-pinned composites is the crimping of in-plane fibres caused by the insertion of the pins, which weakens the in-plane static and fatigue properties of laminate $[10,11]$. In the context of nano-reinforcements, Lubineau and Rahaman [12] have shown in their review of nanofiller reinforced fibre-composite laminates that the improvement in the delamination fracture resistance of these composites is typically of the order of $100 \%$ except when the nano-reinforcements are aligned in the through-thickness direction using chemical vapour deposition (CVD). Veedu et al. [13] used chemical vapor deposition (CVD) technique to incorporate $2.0 \mathrm{wt} \%$ of an aligned CNT forest into fibre-epoxy composite laminates which led to an $280 \%$ increase in their mode I fracture energy. However, the temperature required for achieving direct CVD growth of aligned CNTs onto fibre preforms is well in excess of $750{ }^{\circ} \mathrm{C}$ which damages the structural fibres. For instance, the coating of IM7 carbon fibres with CNT via direct CVD growth at $800{ }^{\circ} \mathrm{C}$ resulted in their tensile strength being reduced by about 70\% [14]. Thus the resulting fibre-composites may have significantly reduced inplane properties.

By comparison, natural composite materials, such as bone and nacre, have evolved elaborate hierarchical architectures to achieve structures that are both strong and tough, using weak but readily available building blocks [15]. Natural composite materials that combine the desirable properties of their sub-components often perform significantly better than the sum of their parts, representing a major synergistic improvement through the confluence of mechanisms that interact at multiple length scales [16]. This has led to the current interest in bioinspired composite design ideas [16-18]. However, very few examples of practical synthetic versions of the complex hierarchical architecture of natural composites have been reported [19]. Almost all natural materials comprise of a relatively small number of polymeric (proteins) and ceramic (for instance calcium carbonate) components or building blocks which have relatively poor intrinsic properties [17]. The superior traits of natural composites stem from naturally-occurring complex architectures utilizing different structures or structural orientations of constituents spanning nano- to macro-scales [19]. For instance, in natural composites, such as nacre or bone, the ceramic phase is often in the form of nanometre grains, 
nanofibres or nanoplatelets, all of which increase flaw tolerance and strength [15]. In contrast, most humanengineered composites have been developed through the formulation and synthesis of new compounds, for instance, different fibres or polymeric matrices, and with structural control primarily at the micrometre scale [5].

5 The purpose of the present work is to demonstrate a novel approach for toughening fibre-reinforced composite architecture with structural reinforcements spanning multiple length scales and orientations as shown in Fig 1. Carbon-fibre epoxy composites are reinforced in the through-thickness direction using a combination of nano-scale carbon nanofibers (CNFs) and macro-scale carbon z-pins. CNFs of 0.82 vol\% with random orientation are incorporated in the epoxy matrix while z-pins of 0.5 vol\% are inserted in the through-the-thickness direction of the laminate. The focus of this paper is to investigate the hybridisation effect of concurrent reinforcements by CNFs and z-pins on the mode I interlaminar fracture toughness and fatigue properties of carbon-fibre epoxy laminates. To this end, the toughening and fatigue strengthening mechanisms of multi-scale reinforcements are characterised experimentally, including the impact of CNFs in the matrix on the z-pin bridging traction load under mode I static and fatigue loadings. The experimental data and fractographic observations presented in this paper provide new and important findings on the microstructure and parameters that control the fracture toughness and fatigue properties of multi-scale composites and lead to a new class of multi-scale fibre composites.

\section{Materials and Experimental Methodology}

\subsection{Multi-scale material designs}

As a prime example of a damage-tolerant natural composite material, bone combines strength with toughness via a multitude of deformation and toughening mechanisms operating at different length scales $[15,20,21]$. The fracture resistance in bone can be separated into intrinsic mechanisms that promote ductility and extrinsic mechanisms that act to 'shield' a growing crack [19]. In bone, the intrinsic toughness originates at the nanometre length scale through various processes, including stable uncoiling of the mineralized collagen components and the process of collagen fibrils (of $\sim 1.5 \mathrm{~nm}$ diameter and $\sim 300 \mathrm{~nm}$ long) sliding as shown in Fig. 1a. The fibrillar sliding mechanism promotes plasticity near the crack tip at nano- and micro-length scales [15]. This intrinsic toughening mechanism results in relatively large energy dissipation within the plastic zone and serves to blunt the crack tip, while reducing the driving force for cracking. Recent nanocomposite research has demonstrated that similar intrinsic toughening can be realised in polymeric matrices at the nano-scale via nano-reinforcements such as carbon nanofibres (CNFs) [22-24], carbon nanotubes (CNTs) [25, 26] and graphene nanoplatelets (GNPs) [27, 28]. The inclusion of nanoreinforcements in polymeric matrices may significantly enhance energy-dissipative deformation mechanisms of the polymer in the form of void growth, for example, which promotes the formation of plastic zones as shown in Fig 1b. In addition, an even greater improvement to the polymer toughening 
occurs via the pull-out of nano-reinforcements from the polymer matrix which dissipates energy through frictional sliding [29]. The nano-reinforcement pull-out process also leads to the formation of a crackbridging zone near the tip, which opposes the applied stress for cracking [30]. As shown in Fig 1(a-b), this frictional sliding process in human-engineered composites is analogous to the fibrillar sliding mechanism observed in bone. However, an even greater contribution to the fracture resistance of bone arises from an extrinsic toughening mechanism that occur behind the crack tip at longer length scales, in the range of 10$100 \mu \mathrm{m}$ [20]. Specifically, once the crack begins to grow, mechanisms within the crack wake are activated in the form of crack bridging by the osteons to inhibit further cracking [31]. As the crack continues to grow, the regions between microcracks formed at the osteonal interfaces form the uncracked-ligament bridges, which act as intact regions spanning the crack wake to inhibit its progress. Any pull-out of the osteons from the bone matrix that may occur will promote toughening once crack propagation has begun. Such crack bridging toughens normal bone by decreasing the crack-tip stress intensity, and a larger applied force is required to propagate the crack further. This type of extrinsic toughening mechanism can be realised using z-pinning technique, where thin carbon-fibre z-pins (of $\sim 280 \mu \mathrm{m}$ diameter) are inserted in the thickness direction (see Fig 1b) of a laminate [32, 33]. However, the advent of nanotubes and nanofibres has opened possibilities of attaining additional intrinsic toughening mechanisms at previously unattainable scales in combination with the extrinsic toughening, as is shown in Fig. 1b. The present work will focus on understanding and demonstrating the synergistic toughening of fibre composites through the use of nanoscale (i.e. CNFs), micro-scale (i.e. carbon fibres) and macro-scale (i.e. z-pins) reinforcements forming a three-dimensional architecture mimicking tough natural composites. Such multi-scale composites can be used in aerospace, automotive and marine applications where impact-induced delamination damage is a major design consideration.

\subsection{Composite materials and reinforcement process}

Four different types of composites were manufactured for testing. The first configuration comprised the baseline laminate, which was fabricated using 20 plies of a 200 gsm plain woven T300 carbon fabric (AC220127 supplied by Colan Ltd.) and a bisphenol-A based epoxy resin (Resin-105 and Hardener-206 supplied by Westsystem $\left.{ }^{\circledR}\right)$. The plies were oriented such that the weft and warp tows were along the length and width of the laminate, respectively. The chosen Westsystem-105 resin is widely used for marine applications where the operating temperature of its fibre composite system is typically limited by the glass transition temperature (i.e. $\sim 70^{\circ} \mathrm{C}$ ) of the cured epoxy resin [34]. (However, the information on the moisture absorption rate of this resin system is currently unavailable from the supplier or the published literature.) The carbon-fibre epoxy laminate was made using a wet hand-layup process. The laminate was cured at room temperature with $350 \mathrm{kPa}$ overpressure in a hydraulic press for 24 hours, and then post-cured at room 
temperature for 48 hours to allow the epoxy to reach its working strength in accordance with the epoxy 2 supplier's recommendations [34].

3 The second type of composite material consisted of a CNF-reinforced laminate made by incorporating 4 commercially available CNFs (Pyrograf® - III, grade PR-24-XT-HHT supplied by Applied Sciences Inc.), 5 which have a diameter of about 70-200 nm and a length of 50-200 $\mu \mathrm{m}$. The addition of CNF to the epoxy 6 resin leads to a significant increase in its viscosity [35]. Therefore, a moderate CNF weight content (i.e. 1 during the wet layup process. Nevertheless, in our previous investigations on the optimum loading of CNF in epoxy, we observed that addition of just $1 \mathrm{wt}$.\% CNFs can promote large improvements to the fracture energy of epoxy matrices with only a moderate increase in its viscosity [24, 28]. Firstly, 1 wt.\% (i.e. 0.82 vol.\%) of the CNFs were hand-mixed with the epoxy resin (without the hardener) and solvent-free acrylate copolymers, namely Disperbyk-191 and -192 (supplied by BYK®), to aid the dispersion of the CNFs. The dispersive surfactants that were added to the CNFs were equal to the weight of CNFs, resulting in a mixture of CNFs:D-191:D-192 at a weight ratio of 1:1:1. The addition of the dispersion aiding surfactants was found to have no effect on the fracture toughness of the bulk epoxy. The CNF/epoxy mixture was then passed four times through the three-roll mill at $150 \mathrm{rpm}$ with progressively smaller gap size until the smallest gap setting of $20 \mu \mathrm{m}$ had been reached. The hardener was then added to this mixture followed by a wet hand layup to produce the carbon-fibre laminate, which was processed and cured under the same conditions as the control material described above.

The third and fourth types of composites were made by z-pinning the baseline material (i.e. without any CNFs present) and the CNF-reinforced carbon-fibre epoxy laminates, respectively. They were then cured in the hydraulic press. The z-pins used were $280 \mu \mathrm{m}$ diameter pultruded rods of unidirectional carbon fibrebismaleimide (supplied by Albany Engineered Composites Pty Ltd.). By controlling the average spacing to $3.5 \mathrm{~mm}$, the volume content of the z-pins was set to be $0.5 \mathrm{vol} \%$. The in-plane strength and stiffness of zpinned laminate decrease approximately linearly with increasing volume content of the pins [3, 36]. Thus, a low 0.5 vol.\% of z-pins was chosen for through-thickness reinforcement of the laminate and the presence of 0.5 vol.\% of z-pins is reported to cause less than $2 \%$ and $4 \%$ reduction in the compressive and tensile strengths of the laminate, respectively [3]. The same layup procedure and processing conditions were applied to the z-pinned laminate and the laminate reinforced with both CNFs and z-pins. Although the length of the as-supplied z-pins within its carrier was $9 \mathrm{~mm}$, the length of the z-pins within the laminate was controlled by the actual thickness of the carbon-epoxy laminate, which was $5 \mathrm{~mm}$. As shown in Fig. 2, an additional layer of balsa wood with $4 \mathrm{~mm}$ thickness was placed at the base of the wet layup laminate in order to accommodate the excess length of the z-pins during the z-pinning process. The traditional ultrasonicallyassisted pinning process used for the carbon-epoxy prepreg system was not necessary due to the soft nature of the wet layup laminate. Instead, z-pinning in the through-thickness direction was achieved by simply 
3 laminates were fully cured.

4 Double cantilever beam (DCB) specimens were employed for the tests described in the following sections;

compressing the z-pin laminate assembly within the hydraulic press with a pressure of $350 \mathrm{kPa}$. The excess z-pin length within the carrier and the base balsa wood were trimmed with a vibrating saw blade after the they consisted of $230 \mathrm{~mm}$ long, $20 \mathrm{~mm}$ wide rectangular-shaped coupons. The DCB specimens consisted of a central region made from wet layup plain woven carbon-epoxy laminate and outer regions that were used to provide additional stiffening and strengthening, as shown schematically in Fig. 3. One end of the specimen contained loading tabs as well as a $50 \mathrm{~mm}$ long, and $25 \mu \mathrm{m}$ thick polytetrafluoroethylene (PTFE) film was placed between the two middle plies to act as a pre-crack for initiation of the delamination crack. To prevent the sub-laminate arms of the DCB specimens from breaking during testing, each specimen was bonded with two 12-ply unidirectional carbon-epoxy composite strips using an epoxy-paste adhesive (Araldite 420 supplied by Huntsman ${ }^{\circledR}$ ).

\subsection{Fracture toughness and cyclic-fatigue testing procedures}

Both the static fracture toughness and the delamination cyclic-fatigue growth properties of all four types of composite materials were measured using the DCB specimens described above. Mode I fracture toughness testing was conducted under displacement controlled using a screw-driven Instron testing machine with a 10 $\mathrm{kN}$ load cell. The interlaminar fracture toughness was measured by monotonically loading the arms of the specimen (via the bonded-on end blocks) using a displacement rate of $2 \mathrm{~mm} / \mathrm{min}$, in accordance with the ASTM Standard D5528 [37]. The crack length was measured using a travelling optical microscope located at one side of the DCB specimen. A white correction fluid was applied to one side of the DCB facing the travelling microscope in order to improve the visibility of the delamination crack growth. During loading the delamination crack grew uniformly across the width of the specimen, so measurement was only needed on one edge. Four specimens were tested for each of the four materials.

Mode I interlaminar cyclic-fatigue testing was performed by applying a constant amplitude sinusoidal cyclic load at a frequency of $10 \mathrm{~Hz}$. The tests were performed using a computer-controlled Instron E3000 system with a $3 \mathrm{kN}$ load cell under displacement control with a constant cyclic ratio ( $R$-ratio). The ratio between the minimum and the maximum applied displacement in one load cycle was kept constant at 0.5. Initially, the specimens were subjected to quasi-static loading and the delamination was allowed to grow by $\sim 15 \mathrm{~mm}$ from the initial flaw in order to achieve a naturally sharp crack. The specimens were then subjected to cyclic fatigue loading with the maximum crack opening displacement being chosen such that the initial value of the applied strain-energy release-rate was about $80 \%$ of the mode I interlaminar fracture toughness determined from the quasi-static tests. Delamination fatigue growth rates were measured at crack growth intervals of $\sim 1$ mm, in accordance with the load-shedding scheme prescribed in ASTM E647 [38]. The load-shedding 
1 process was continued until the crack growth rates reached the threshold value and no further delamination

2 growth occurred.

$3 \quad 2.4$ Static and fatigue z-pin pull-out tests

4 Z-pin pull-out tests were performed to assess the influence of the CNF reinforcement of the matrix on the 5 crack-bridging traction law of the z-pins. Fig. 3b shows the schematic of the z-pin pull-out test specimens, 6 which were manufactured from the same carbon-fibre epoxy laminate and with similar curing conditions as 7 discussed earlier. Two separate batches of specimens were manufactured with one using CNF-reinforced 8 matrix and the other without the CNFs being present. The specimens were z-pinned at 0.5 vol.\% in a 4 x 3 9 configuration. A thin film of polytetrafluoroethylene was placed between the two middle plies to keep the 10 two laminates unbonded to facilitate the z-pin pull-out. The quasi-static z-pin pull-out tests were conducted

11 by loading the specimens in the through-thickness direction at a rate of $0.5 \mathrm{~mm} / \mathrm{min}$ until the laminates 12 became separated. The separation of the samples was measured using a crack-opening displacement gauge.

13 The z-pin bridging traction load was determined by dividing the measured load by the number of pins within 14 the specimen.

15 The degradation to the z-pin friction traction load under fatigue cycling was investigated using the test 16 procedure outlined by Zhang et al. [39]. The fatigue z-pin pull-out testing was performed under 17 displacement control by applying a triangular waveform with a frequency of $0.05 \mathrm{~Hz}$. A monotonic 18 increasing load was first applied until the z-pins fully debond from the laminate. Then the displacement at 19 which the z-pins fully debond from the matrix was used as the minimum cyclic displacement $\left(\delta_{\min }\right)$ for 20 fatigue testing. The maximum cyclic displacement was found to follow the relationship:

$21 \delta_{\max }=\delta_{\min }+0.2 l$

22 where $l$ is the z-pin length $(=5 \mathrm{~mm})$. The z-pin bridging traction load was measured up to a total of 5000 fatigue cycles.

\subsection{Tensile testing procedure}

Tensile tests were performed to assess the influence of z-pin and CNF reinforcement on the strength and stiffness of the laminates. Dog-bone shaped tensile test coupons with a $14 \mathrm{~mm}$ wide gauge section were fabricated using water-lubricated precision grinding machine. Tensile test was performed on a MTS testing machine with a $100 \mathrm{kN}$ load cell. The tensile test was performed using a displacement rate of $2 \mathrm{~mm} / \mathrm{min}$ in accordance with the ASTM standard D3039 [38]. Four tensile specimens were tested parallel to the warp tows to determine the average tensile strength and stiffness of each laminate type.

\section{Results and Discussion}


1 Fig. 4 shows the typical effect of the through-thickness reinforcements on the mode I crack growth resistance (R-curve) behaviour of the carbon-fibre epoxy laminates under quasi-static loading, and shows the effect of the through-thickness reinforcement size on the interlaminar fracture toughness. The R-curve for the control laminate increased slightly over the initial $10 \mathrm{~mm}$ of delamination extension, and this is due to the carbon fibres crossing over and bridging the crack faces [40]. As shown in Fig. 4, the R-curve for the CNF reinforced laminate increased rapidly during the initial 15-20 mm phase of crack growth and then reached a steady-state. This toughness increase was due to the intrinsic toughening in the form of CNF debonding and subsequent matrix void growth (see Fig. 5a-b) as well as the extrinsic toughening in the form of CNF pull-out and crack bridging, as shown in Fig. 5a,c. These toughening mechanisms are commonly observed in nanofiller-reinforced laminates [6, 7, 41]. In comparison, the R-curve for the z-pinned laminate increased at a much faster rate and reached a higher toughness than the unpinned laminates. This was due primarily to the evolution of a z-pin bridging-zone which spanned $\sim 30 \mathrm{~mm}$ of the crack, as shown in Fig. 5d-e. Most importantly, from Fig. 4 it is seen that the steady-state interlaminar fracture toughness measured for the laminate reinforced concurrently with CNFs and z-pins was much higher than when these reinforcements were used separately. This was due to the synergistic combination of toughening by CNFs at the crack tip and the extrinsic toughening in the crake wake via a long z-pin crack-bridging process zone, as shown in Fig 5f-g. This synergistic toughening is discussed in detail below.

Fig. 6 shows the effects of using CNF and z-pin reinforcements concurrently and separately on the initiation, $G_{I i}$, and steady-state interlaminar fracture toughness, $G_{I c}$, of the laminate. The initiation fracture toughness of the laminate reinforced with z-pins was slightly greater (by $30 \%$ ) than the unreinforced (i.e. 'control') laminate. The z-pins promote very little resistance to crack initiation at relatively low volume fractions ( $\sim 0.5$ vol.\%) [32]. This is due to the much greater inter-pin distance ( $\sim 3.5 \mathrm{~mm}$, as seen in Fig. 5de) in comparison to the small-scale length of the crack initiation process zone: z-pins are only effective when the delamination crack is much longer than the inter-pin distance. However, the initiation toughness of the CNF reinforced laminate was about 100\% greater than the control laminate. Similarly, when CNF and z-pin reinforcements are used concurrently, the initiation fracture toughness was even higher (by 150\%). CNFs promote high delamination resistance by multiple toughening processes near the crack tip, including intrinsic (i.e. crack bifurcation and matrix void growth, see Fig 5a-b) and extrinsic (i.e. crack bridging and pull-out of the CNFs, see Fig 5c,f). In the process zone ahead of the crack tip, CNFs debond from the matrix due to the presence of triaxial tensile stresses. The debonded CNFs then act as voids within the matrix, enabling the matrix to deform plastically and dissipate energy while enlarging these voids. Matrix void growth around nanofillers is commonly observed to promote intrinsic toughness in nanocomposites [22, 25, 41]. However, in laminated composites, the size of the process zone cannot develop to its full extent, since it is constrained in a thin layer of matrix by plies of fibre on either side [42]. Therefore, relatively less energy is dissipated in the form of matrix void growth. Instead, the majority of the strain energy is dissipated via 
CNF pull-out and the formation of a crack-bridging process zone behind the tip (see Fig $\mathbf{5 c , f}$ ). During CNF pull-out and the formation of the crack-bridging process zone, a large amount of energy is dissipated in the form of interfacial frictional sliding between the CNF and the matrix. Once the CNF bridging process zone

is fully developed, the fracture toughness reaches the steady-state value and remains approximately constant.

The CNF reinforcement increased the steady-state fracture toughness by $~ 70 \%$, which agrees with other studies [6, 12, 43]. Even greater improvements to the steady-state fracture toughness were measured (of 200\%) for the laminates reinforced with z-pins. The z-pins promote a strong extrinsic toughening mechanism behind the crack tip and over a longer length-scale via a long crack-bridging process zone (see the pull-out of $\mathrm{z}$-pins from the laminate. This leads to the formation of the z-pin bridging process-zone in the crack wake, which provides the necessary traction force to shield the crack tip from the applied stress. Importantly, when CNFs and z-pins were used concurrently, they produced a much greater improvement to the steady-state fracture toughness (of $\sim 400 \%$ ) due to toughening processes operative ahead of the tip (via the CNFs) and behind the crack tip (via the z-pins). Furthermore, the overall improvement to the fracture toughness is greater than the expected simple additive effect from the toughening due to CNFs and z-pin separately. This is indicative of a synergistic toughening effect, which is quantified as follows:

$$
\text { Synergy }=\frac{\mathrm{G}_{\mathrm{Ic}(\mathrm{CNF}+\mathrm{zpin})}-\mathrm{G}_{\mathrm{Ic}(\mathrm{Control})}}{\left(\mathrm{G}_{\mathrm{Ic}(\mathrm{zpin})}-\mathrm{G}_{\mathrm{Ic}(\mathrm{Control})}\right)+\left(\mathrm{G}_{\mathrm{Ic}(\mathrm{CNF})}-\mathrm{G}_{\mathrm{Ic}(\text { Control })}\right)}-1
$$

where $G_{I c}$ denotes the mode I steady-state fracture toughness, and the subscripts “control”, “CNF”, “zpin”, and "CNF+zpin" denote the quantities pertinent to the four types of composites. Using the average values of $G_{I c}$ from Fig 6, the level of synergy in the steady-state fracture toughness was calculated to be about $11 \%$ using Eq. (2). The statistical significance of this low level of synergy was determined using a two-way analysis of variance (ANOVA). The two-way ANOVA test calculates the probability of interaction while considering the standard deviation of each sample population. Each sample population had a size of 38, comprised of all $G_{I c}$ values corresponding to the delamination length greater than $30 \mathrm{~mm}$ in Fig. 4. The corresponding values of $p$ and $f$ for interaction were 0.003 and 10.36 respectively which suggests a 99\% probability of synergy when the CNF and z-pins are used concurrently. A possible major reason for this synergy is that the presence of CNFs in the matrix enhances the energy dissipation during the debonding and pull-out of the z-pins. This was further examined by determining the mode I bridging traction load using the z-pin pull-out test. Fig. 7a shows the comparison between a representative bridging traction loaddisplacement behaviour during the pull-out of the z-pins from laminates with CNF reinforced matrix and unmodified matrix. The initial portion of this curve represents the elastic deformation of the z-pin/matrix interface up to the maximum traction load necessary to fully debond the z-pin. The debonding is followed by the subsequent pull-out of the z-pin from the laminate. The area under the traction load-displacement curve defines the total amount of energy dissipated by the elastic deformation, debonding and pull-out of z-pins. 
The maximum traction load necessary to fully debond the z-pin is increased by the presence of CNFs in the matrix. The maximum traction load is limited by the z-pin/matrix interface or the shear strength of the matrix, whichever is the lesser. Several recent fibre pull-out studies have reported up to a 30\% improvement in the interfacial strength $[44,45]$ between micro-scale fibres and the matrix, when the latter was reinforced with nanofillers due to the better flow of the matrix. Other studies have also reported improvements in the interlaminar shear strength in composites with CNF reinforced matrices [8, 46]. The z-pin/matrix interface strength can be determined from the maximum traction load, $P_{\max }$ using [47]:

$$
\tau_{i}=\frac{P_{\max }}{\pi d l_{p o}}
$$

8 where $d$ and $l_{p o}(\sim l / 2)$ are the z-pin diameter and pull-out length, respectively. By using an average value for 9 the maximum traction load measured from five different z-pin pull-out samples, the z-pin interface strength 10 for the unmodified matrix was calculated to be $16.4 \mathrm{MPa}$. This value is very similar to that previously reported for z-pin interface strength measurements [47]. Similarly, the z-pin interface strength for the CNF reinforced matrix was calculated to be 22.1 MPa. A similar enhancement to the z-pin interface strength may be achieved by either using a stronger matrix or by improving the interfacial adhesion via, for example, functionalising the surface of the z-pin. However, simply increasing the interfacial adhesion may not necessarily lead to a greater toughness improvement, because the energy associated with the elastic deformation of the z-pin and its subsequent debonding is much lower than that dissipated during the pin pull-out process. The energy dissipated during the pull-out process for the z-pin is due to the interfacial frictional stress, $\tau_{i f}$, between the z-pin and the laminate. By using the average peak friction load corresponding to the z-pin pull-out stage (see Fig 7a) in Eq. (3), the interfacial frictional stress for the unmodified matrix was calculated to be 7.85 MPa. The interfacial frictional stress for the CNF reinforced matrix was slightly higher at 9.89 $\mathrm{MPa}$. Thus, as generally reported [47], the interfacial frictional stress is indeed lower than the z-pin interface strength.

The energy dissipated during the z-pin pull-out process can be determined from the interfacial frictional stress using [48]:

$G_{\text {pull-out }}=\frac{2 V_{f} \tau_{i f} l_{p o}^{2}}{d_{f}}$

where $V_{f}$ is the z-pin volume fraction. Fig $\mathbf{7 b}$ shows the effect of CNF reinforcement on the energy dissipated during the z-pin pull-out process determined from Eq. (4) and its comparison to the experimentally measured energy from the area under the curve in Fig 7a. Using Eq. (4) the z-pin pull-out energy for various pull-out lengths can be calculated, as shown in Fig $\mathbf{7 b}$. It can be seen that the model predictions correlate well with the experimental results pertinent to a pin density of 0.5 vol\%. Furthermore, the calculated pull-out energy is in agreement with the improvement of the steady-state value of $G_{I C}$ due to 
1 the presence of the z-pins, compared to the control laminate, i.e. about $2 \mathrm{~kJ} / \mathrm{m}^{2}$ as shown in Fig. 6.

2 Moreover, the energy dissipation during the z-pin pull-out from the CNF reinforced matrix was found to be

$3 \sim 25 \%$ greater than the unmodified matrix. This suggests interactions occur between the CNFs and z-pins

4 which lead to significant toughness enhancements. Therefore, the presence of CNFs in the matrix increases

5 the maximum stress of the z-pin debonding process and also increases the frictional energy dissipated during

6 the subsequent pull-out of the z-pin, which is due to the pull-out of additional CNFs at the z-pin/matrix

7 interface, as shown in Fig 8. This enhancement to the energy dissipation during the pull-out of the z-pins in

8 the presence of the CNFs in the matrix leads to the synergistic improvement in the fracture toughness of the

9 laminate that is observed.

\subsection{Cyclic-fatigue tests}

12 Fig. 9 presents the fatigue delamination growth, $d a / d N$, per load cycle against the cyclic strain-energy release-rate range (SERR) for the unreinforced laminate and laminates reinforced with CNFs and/or z-pins.

14 The measured $d a / d N$ versus $\Delta G_{e q}$ curves exhibit the typical Paris relationship, where the term $\Delta G_{e q}$ is 15 defined by $[40,49,50]$ :

$16 \Delta G_{e q}=\left(\sqrt{G_{\max }}-\sqrt{G_{\min }}\right)^{2}$

The above relationship can be extended by using the Forman equation [43] to account for the effects of the threshold and fracture toughness on the crack growth rate, as given by the following relationship [49]:

$\frac{d a}{d N}=\frac{C\left[\Delta G_{e q}-\Delta G_{e q, t h}\right]^{m}}{(1-R)\left[\sqrt{G_{I c}}-\sqrt{\Delta G_{e q}}\right]}$

where $\Delta G_{e q, t h}$ is the threshold value of $\Delta G_{e q}$ and $R$ is the crack opening displacement ratio during fatigue loading. With the values of $\Delta G_{e q, t h}$ and the fracture energy listed in Table 1, the parameters $C$ and $m$ in Eq. (6) can be obtained by curve-fitting the measured fatigue crack growth rates using Eq. (6). (The value of $\Delta G_{e q, t h}$, below which no cyclic-fatigue crack will occur from the pre-existing delamination, was taken at a crack growth rate of $10^{-9} \mathrm{~m} /$ cycle.) Similar to the results for the quasi-static interlaminar tests, the resistance to fatigue loading was much greater for the laminate reinforced with CNFs and z-pins concurrently. Indeed, the value of $\Delta G_{\text {eq,th }}$ increased by $\sim 40 \%$ for the CNF reinforced and $\sim 300 \%$ for the z-pin reinforced laminates. However, when the laminate was reinforced together with both CNFs and z-pins concurrently, the value of $\Delta G_{e q, t h}$ was much greater and increased by $\sim 400 \%$ compared to the control laminate. Similarly there was a much greater reduction in the gradient of the crack growth rate, as defined by the Paris exponent $m$ (see Eq. 6 and values given in Table 1) for the laminate reinforced with CNFs and z-pins concurrently. The value of the exponent, $m$, defines the sensitivity of the crack growth rate of a material to variations in the applied range of cyclic SERR. A lower value of $m$, in part, indicates a greater resistance to fatigue crack growth. In contrast, the value of $m$ measured for the laminates reinforced with CNFs and z-pins separately, 
was only slightly lower than the control laminate. Similar to the quasi-static interlaminar tests, the toughening due to CNF pull-out and crack bridging near the tip caused the improvement to the cyclic fatigue delamination resistance in the CNF reinforced laminate. For the z-pinned laminate, the fatigue-induced delamination growth caused the formation of a large-scale z-pin bridging zone along the crack wake. This zpin bridging zone generated traction loads that slowed the fatigue crack growth rate under cyclic loading. However, for the laminate reinforced with CNFs, the improvement in the value of $\Delta G_{e q, t h}$ was somewhat lower than the improvement seen in the fracture energy during quasi-static loading of this laminate. This was due to the degradation of the CNF bridging zone near the crack tip caused by the fatigue-induced damage of the CNFs. For example, Fig. 10 shows the fatigue-induced damage of the CNFs on the fracture surface of the CNF reinforced laminate tested under fatigue loading. The outer primary load-bearing CNF wall appears to have been damaged by the fatigue loading, which resulted from the smaller diameter innercore carrying only a portion of the applied load due its lower stiffness.

Next, the question arises of whether, when CNF and z-pin reinforcements are used concurrently, is the improvement to $\Delta G_{e q}$ much greater than expected simply from an additive effect from the toughening due to the CNFs and z-pin acting independently? Since, the former would represent a major synergistic toughening mechanism. Here the apparent synergy in fatigue resistance can be calculated by replacing $G_{I c}$ in Eq. (2) with $\Delta \mathrm{G}_{e q}$ :

Synergy $_{\text {Fatigue }}=\frac{\Delta \mathrm{G}_{\text {eq(CNF+zpin })}-\Delta \mathrm{G}_{\text {eq(Control })}}{\left(\Delta \mathrm{G}_{\text {eq(zpin })}-\Delta \mathrm{G}_{\text {eq }(\text { Control })}\right)+\left(\Delta \mathrm{G}_{\text {eq }(\mathrm{CNF})}-\Delta \mathrm{G}_{\text {eq }(\text { Control })}\right)}-1$

This possible fatigue synergy refers to the SERR range, $\Delta G_{e q}$, necessary to cause a given fatigue crack growth rate of $d a / d N$. The results are presented in Fig. 11. When the CNF and z-pin reinforcements are used concurrently, the level of improvement to the $\Delta G_{e q}$ near the threshold range ( $13 \%$ ) is very similar to the synergistic improvement observed in the quasi-static fracture toughness of this laminate, which was $11 \%$. The apparent synergistic improvement was, however, much greater ( 35\%) at higher growth rates and, hence, at higher values of $\Delta G_{e q}$, i.e. when the crack growth rate exceeded $\sim 10^{-6} \mathrm{~m} /$ cycle (see Fig. 11). However, this apparent synergy in the fatigue resistance has been found to be statistically insignificant by using a two-way analysis of variance (ANOVA). The large scatter of about one order of magnitude observed in the crack growth rates leads to a high $p$-value of 0.679 , which implies that the interaction is statistically improbable.

Studies have shown that fatigue damage of the z-pin/laminate interface can result in early onset of interfacial debonding of z-pins which eventually leads to their failure by pull-out [32, 39]. To further investigate the influence of CNFs on the z-pin/laminate interface properties, additional cyclic-loading pin pull-out tests were conducted. Fig. 12 shows the influence of CNFs on the friction traction load generated during the cyclic pull-out of z-pins, and a comparison to quasi-static test results. As seen in Fig. 12a, there is a progressive reduction in the friction traction load generated by z-pins with increasing number of 
displacement cycles. This reduction is due to the wearing of the z-pin/laminate interface caused by the cyclic pull-out of the pins [28]. Fig. 13 shows images taken inside the holes created from z-pin pull-out in the specimens tested under quasi-static or fatigue loading. The hole-wall surface was relatively smooth when the pins were pulled-out under quasi-static loading. Under cyclic loading there was significant wearing of the hole surface, since during cyclic loading the z-pins slid back and forth against the laminate with each load cycle. This resulted in a fretting-type wear process which caused widening of the hole around the debonded z-pin. This then led to the progressive reduction in the friction traction stress generated by the z-pins with increasing number of load cycles as shown in Fig. 12a. A comparison of the peak z-pin friction traction load pin/laminate interface under cyclic loading. As seen in Fig. 13c, the fretting-type wear process is less severe for the z-pin/laminate interface reinforced by CNFs. This is because the CNF nano-reinforcement acts to ine shear strength of the conposite matrix $[8,46]$. For example, Fig. 13d shows that the bridge the micro-cracks that form during the shear deformation of the z-pin/matrix interface due to a cyclic pull-out process and reduce the fretting-type wear action. In z-pinned DCB laminates, the severity of the fretting-wear was observed to increase with $\Delta G_{e q}$. Since at higher $\Delta G_{e q}$ values, the sliding distance in each cycle increases, this can lead to a greater amount of fretting-type wear of the z-pin/laminate interface. However, at such high $\Delta G_{e q}$ values, the CNF reinforcement to the z-pin/laminate interface demonstrated a greater influence on the fatigue performance of the z-pins. This explains the greater level of improvement observed at higher $\Delta G_{e q}$ values for the laminate reinforced with both CNFs and z-pins.

The rupturing or 'un-coring' type of cyclic damage to the CNFs which caused the degradation of the crackbridging zone of the CNFs was rarely observed on the fracture surface of the laminate reinforced with CNFs and z-pins concurrently. This suggests that, under fatigue loading, the z-pin bridging zone and the resultant traction load shields the CNF bridging zone at the crack tip, leading to the significantly greater improvement in the value of $\Delta G_{e q, t h}$ that was observed when CNFs and z-pins were used concurrently, see Table 1.

In addition, tensile tests were performed to assess the influence of through-thickness reinforcement on the in-plane properties of the laminates. The tensile strength $\left(\sigma_{11}\right)$ and Young's modulus $\left(E_{11}\right)$ of the laminates are listed in Table 1. The stiffness of the through-thickness reinforced laminates is very similar to the control laminate. However, the tensile strength of the z-pinned laminates decreased by 2 to $4 \%$. Previous studies have also reported that a greater reduction occurs in the tensile strength of z-pinned laminates in comparison to the reduction in their stiffness [36]. The magnitude of the reduction in the strength of laminates reinforced with $0.5 \mathrm{vol} . \% \mathrm{z}$-pins is similar to that reported in other studies [3]. The reduction in strength is attributed to the crimping of in-plane fibres caused by the inserted z-pins, which increases the stress concentration around these regions of the laminate [3,11]. As a result, all z-pinned tensile specimens were observed to fail along the z-pin region. The CNF reinforcements caused a marginal improvement in the 
strength of the laminates. But this improvement was not sufficient to offset the degradation in strength due

2 to the z-pins.

\section{4. Conclusions}

4 The effects of multi-scale toughening of carbon-epoxy laminates using carbon nanofibres and z-pins 5 spanning multiple length scales have been investigated. The results show that CNFs are effective at 6 improving the interlaminar fracture toughness under quasi-static loading by intrinsic (i.e. crack bifurcation or branching and epoxy void growth) and extrinsic (i.e. crack bridging and pull-out of the CNFs) mechanisms. By comparison, z-pins generate significant extrinsic toughening primarily behind the crack tip and over a larger length-scale via crack bridging. When used concurrently, the interaction between the CNFs and z-pins has been shown to yield a greater toughness than when the two reinforcements are used separately. In particular, the presence of CNFs in the matrix enhanced the energy dissipation during the pullout of the z-pins; indeed, this represented a major synergy suggesting a multiplicative toughening effect. The presence of a synergistic effect was indeed confirmed for the quasi-static toughness results via a statistical analysis. However, the tensile strength of the z-pinned laminates was slightly lower than that of the control laminates. The addition of the CNF reinforcement to the z-pinned laminates was insufficient to recover this loss of strength.

The multi-scale reinforcement to the laminate via CNFs and z-pins also leads to a strong improvement in the resistance to cyclic-fatigue delamination growth over the entire range of crack growth rates from the threshold regime to instability. The improvement in the fatigue delamination resistance has been found to increase with delamination growth, due to the greater effects of the CNF reinforcement on the z-pin/laminate interface under fatigue loading at relatively high cyclic loads. Although there was an initial suggestion of synergistic improvement to the fatigue resistance when the laminate was reinforced by both CNFs and zpins, it was statistically insignificant and therefore the overall improvement was largely additive from these two reinforcements.

A new class of multi-scale fibre composites has been described which offers a unique opportunity to markedly enhance the fracture toughness and fatigue resistance of polymer matrix fibre composites, and hence significantly increase the damage tolerance of such composites over multiple length-scales of delamination cracking from sub-micron to sub-meter scales, which has previously not been possible. It is feasible that other types of carbon nanoreinforcements (e.g. CNTs, grapheme) and z-pins (e.g. metals) promote similar or even greater interlaminar strengthening, and this is currently under investigation.

\section{Acknowledgements}

The authors kindly acknowledge the technical assistance of the RMIT Materials Testing Laboratory team and the RMIT Microscopy and Microanalysis Facility (RMMF) team. The authors are thankful for the 
1 financial support received from the Australian Research Council’s Discovery Grant Program 2 (DP140100778).

3 
1 Table 1 Tensile and fatigue delamination properties of the laminates.

\begin{tabular}{cccccccc}
\hline Specimen & $\begin{array}{c}\boldsymbol{G}_{\boldsymbol{I c}} \\
\left(\mathrm{J} / \mathrm{m}^{2}\right)\end{array}$ & $\begin{array}{c}\Delta \boldsymbol{G}_{\text {eq,th }} \\
\left(\mathrm{J} / \mathrm{m}^{2}\right)\end{array}$ & $\begin{array}{c}\boldsymbol{G}_{\boldsymbol{I c}} \\
\left(\mathrm{J} / \mathrm{m}^{2}\right)\end{array}$ & $\boldsymbol{m}$ & $\boldsymbol{C}$ & $\boldsymbol{E}_{11}$ & $\boldsymbol{\sigma}_{\mathbf{1 1}}$ \\
& 670 & 40 & 670 & 2.2 & $4 \times 10^{-07}$ & $49.6(0.1)$ & $447.5(3.7)$ \\
Control & 1123 & 56 & 1123 & 1.7 & $2 \times 10^{-07}$ & $50.1(0.5)$ & $452.9(4.1)$ \\
CNF & 1922 & 165 & 1922 & 2 & $3.6 \times 10^{-08}$ & $49.3(0.1)$ & $427.6(2.3)$ \\
z-pin & 3255 & 200 & 3255 & 1.4 & $9 \times 10^{-08}$ & $49.3(0.2)$ & $436.7(6.5)$ \\
CNF + z-pin &
\end{tabular}

2 Note: The value of the crack opening displacement ratio during fatigue loading was 0.5. The values in the bracket indicate 3 standard deviations. 
(a)

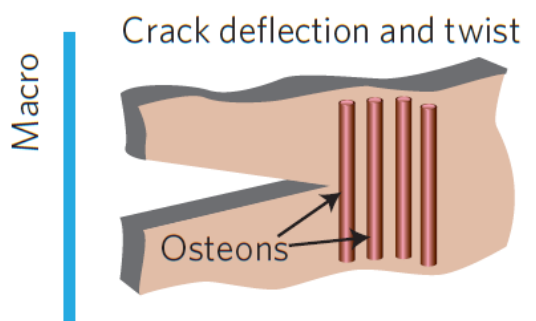

Uncracked-ligament bridging

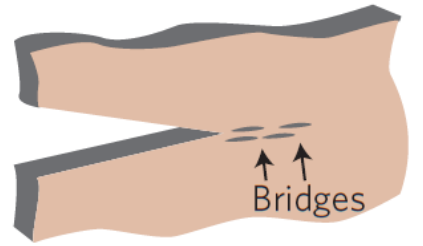

Collagen-fibre bridging

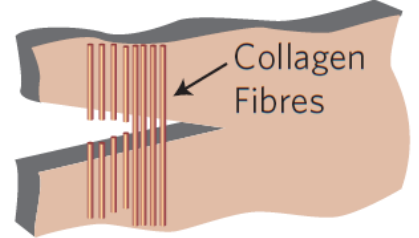

Constrained microcracking

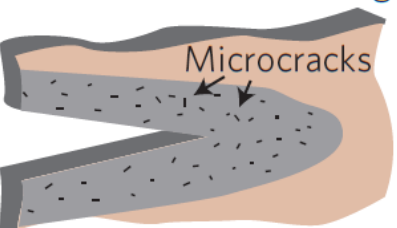

Sacrificial bonds

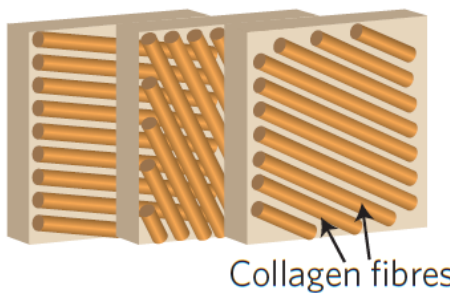

Collagen fibres

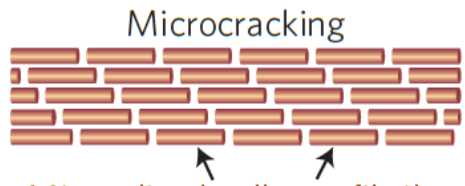

Mineralized collagen fibrils

Fibrillar sliding

Hydroxyapatite crystals

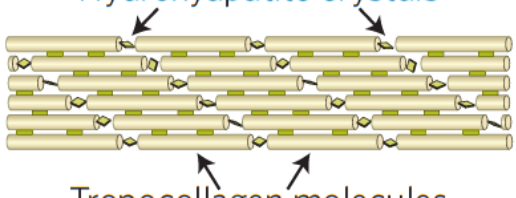

Tropocollagen molecules

Molecular uncoiling

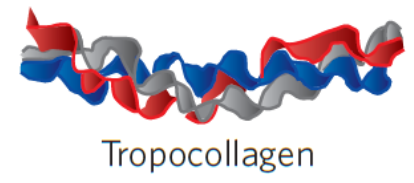

(a)

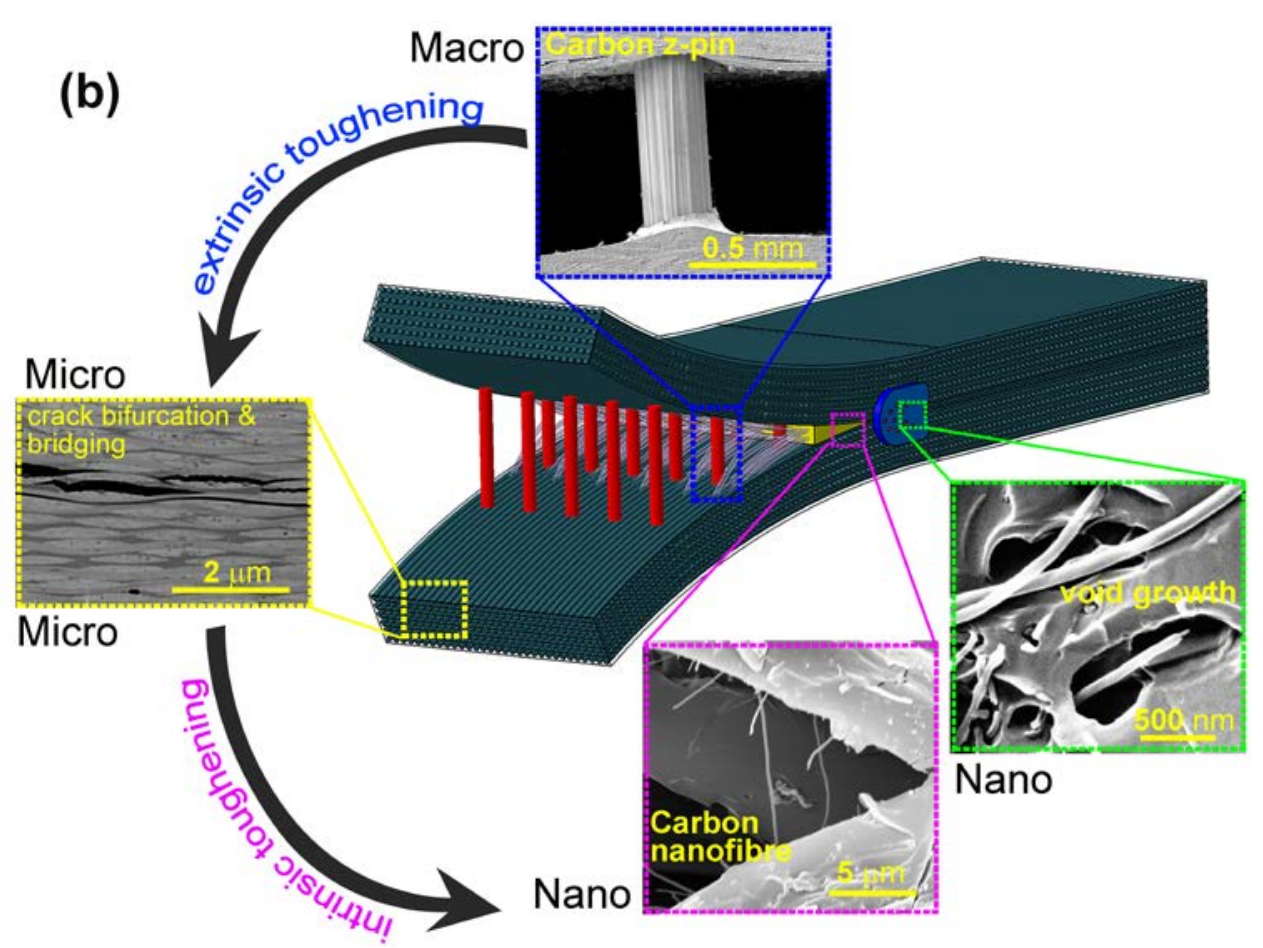

Fig. 1 (a) The various level of hierarchical toughening mechanisms prevailing in a bone. Adapted from [16]

with permission from Macmillan Publishers Ltd Copyright 2014. (b) Schematic representation of the multi-

scale carbon-fibre epoxy composite with toughening processes operating at various scales. 

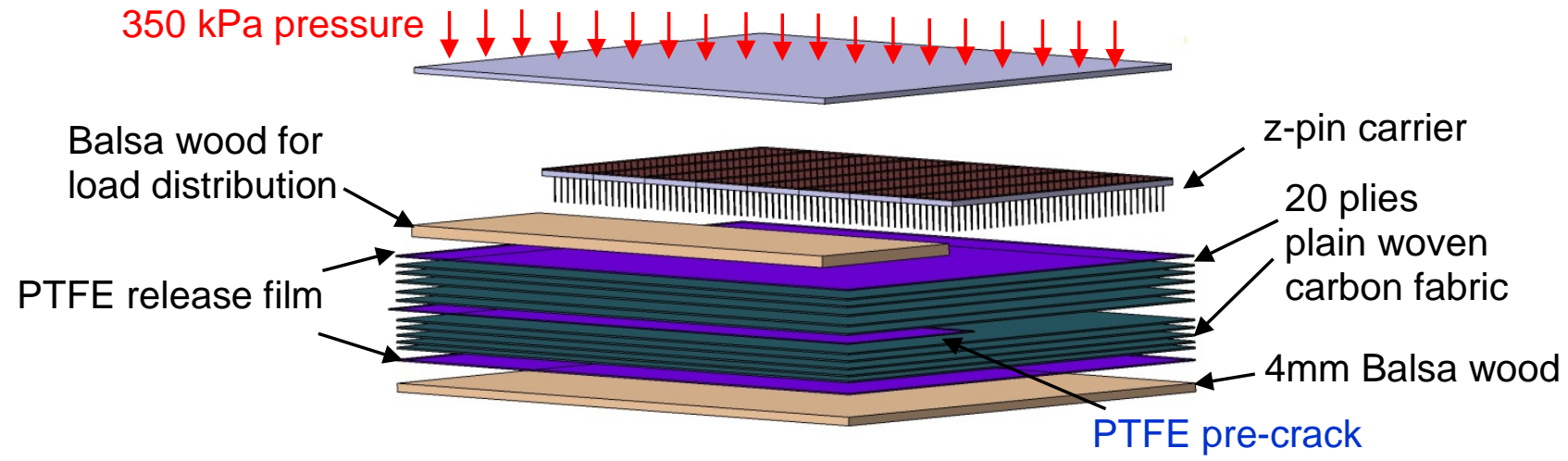

2 Fig. 2 Schematic illustration of the z-pin reinforced carbon-epoxy laminate layup.

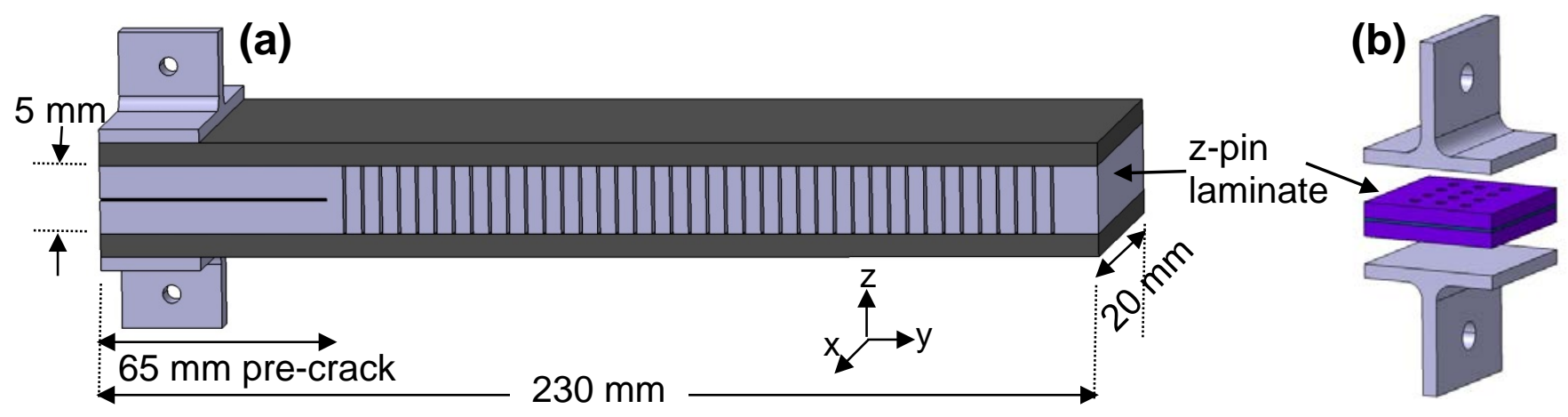

4 Fig. 3 Schematic illustrations of (a) the double cantilever beam (DCB) specimen used for mode I quasi5 static and cyclic fatigue interlaminar fracture toughness testing; and (b) the z-pin pin pull-out test specimen 6 used for measuring the z-pin bridging traction load. (Note: The loading direction for the DCB and pin pull7 out test is along the z-axis.)

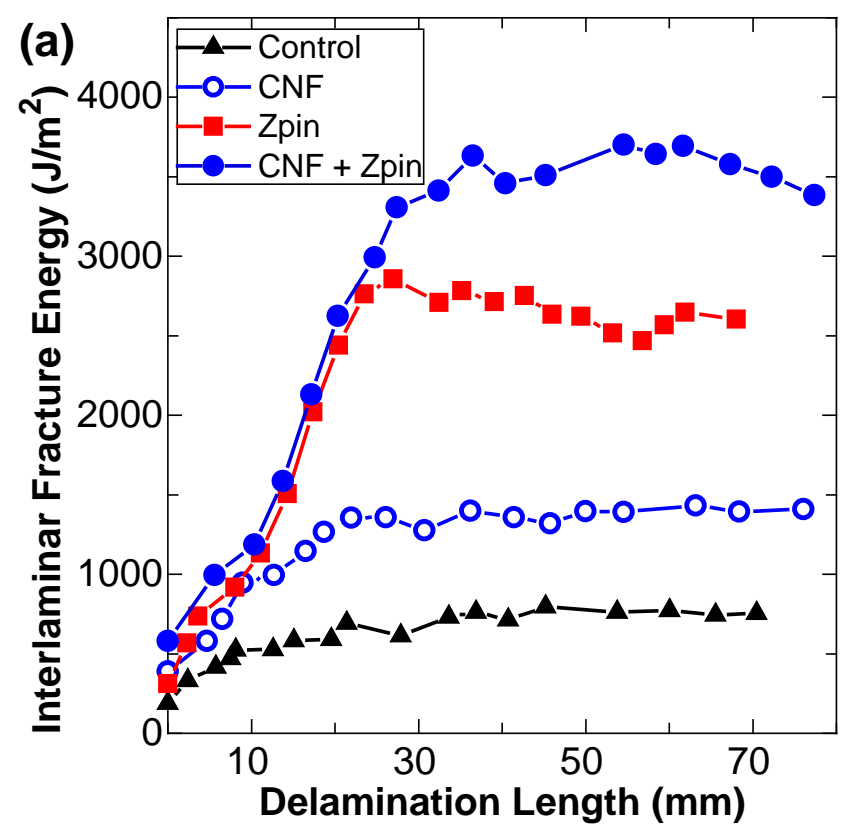

9 Fig. 4 Crack growth resistance (R-) curves for the unreinforced and through-thickness reinforced laminates 10 containing 0.82 vol.\% CNFs and/or 0.5 vol.\% z-pins under quasi-static loading. 

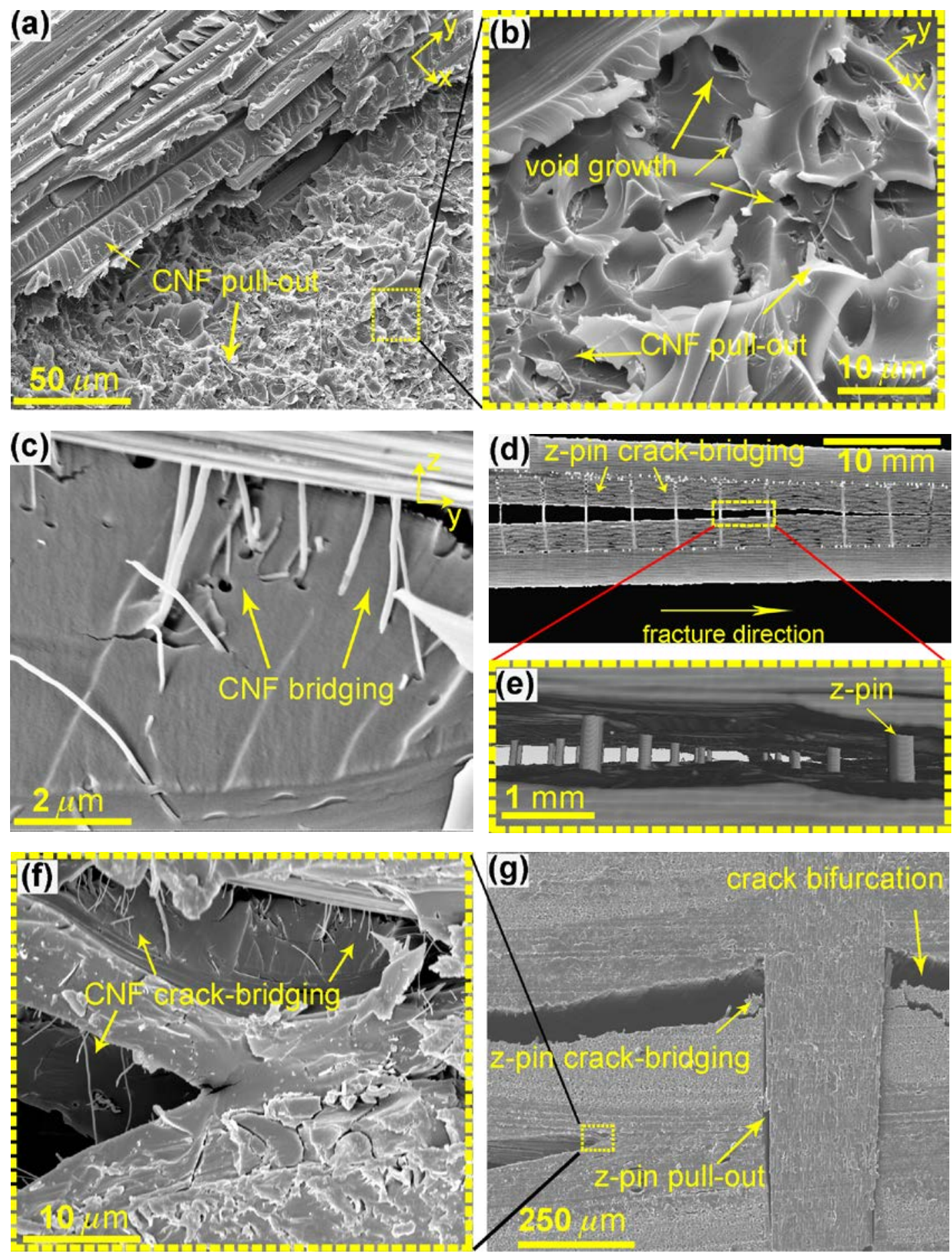

5 Fig. 5 (a-c) SEM micrographs of the 0.82 vol.\% CNF reinforced laminates. (d-e) X-ray computed

6 tomography images showing a side view of a z-pinned DCB test specimen. (f-g) SEM micrographs of the

7 delamination front in a side view for the DCB test specimen containing CNF and z-pin reinforcements.

8 (Note: Please refer to Figure 3 for the DCB z-axis loading direction.) 


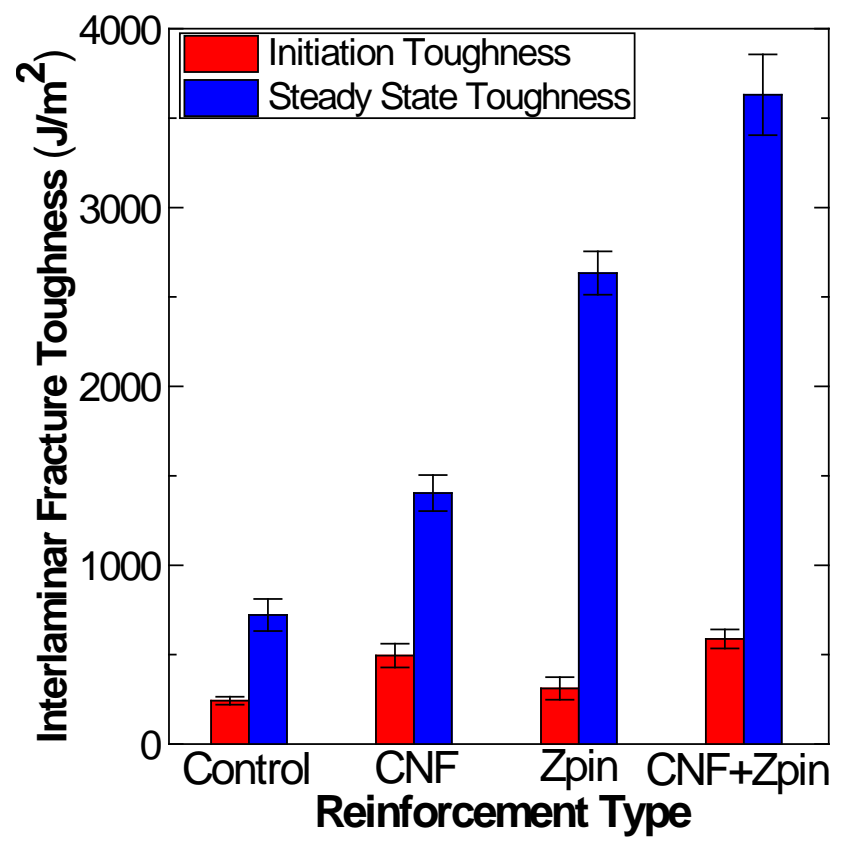

2 Fig. 6 Mode I interlaminar fracture toughness values under quasi-static loading for initiation and 3 propagation of the delaminations in the control laminate and the laminates reinforced with 0.82 vol.\% CNF 4 and/or 0.5 vol.\% z-pins.

5
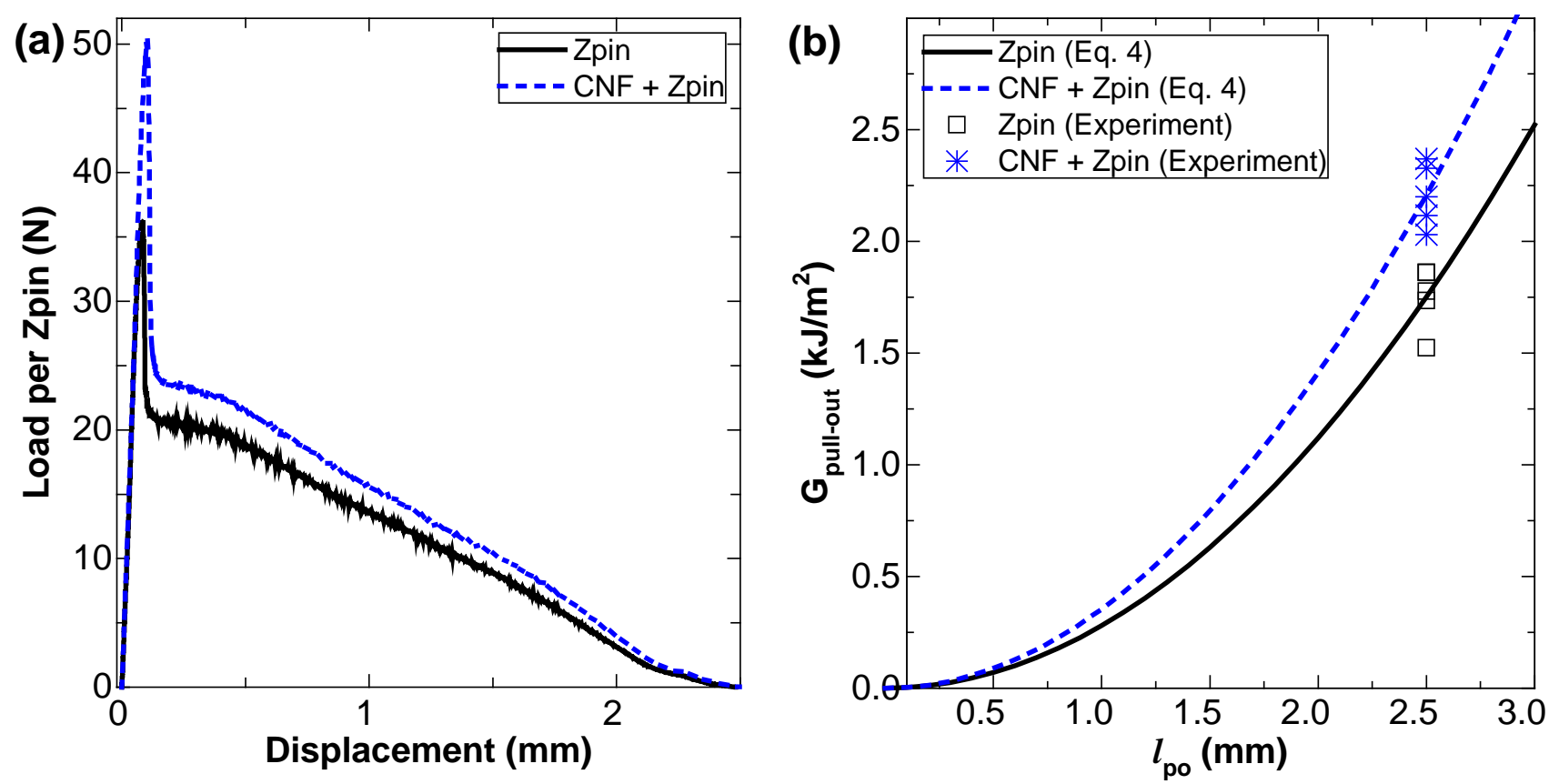

7 Fig. 7 Effects of the CNF reinforced matrix on (a) the z-pin traction load-crack opening displacement curve 8 and (b) the z-pin pull-out energy calculated from (i) the area under the load-displacement curve in (a) and 9 (ii) Eq. (4). 


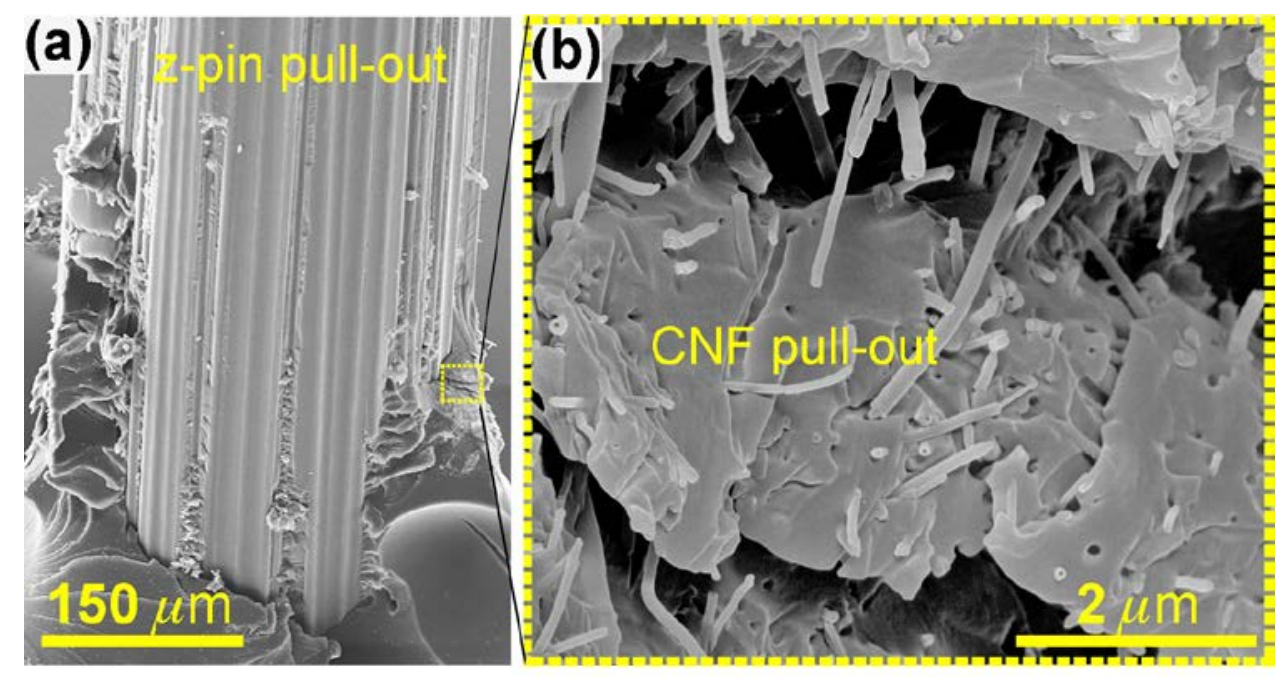

Fig. 8 SEM micrographs of the z-pin surface (b) at low magnification and (c) at high magnification, as 3 observed for the pin pull-out specimens reinforced with CNFs and z-pins concurrently. 4 5 6

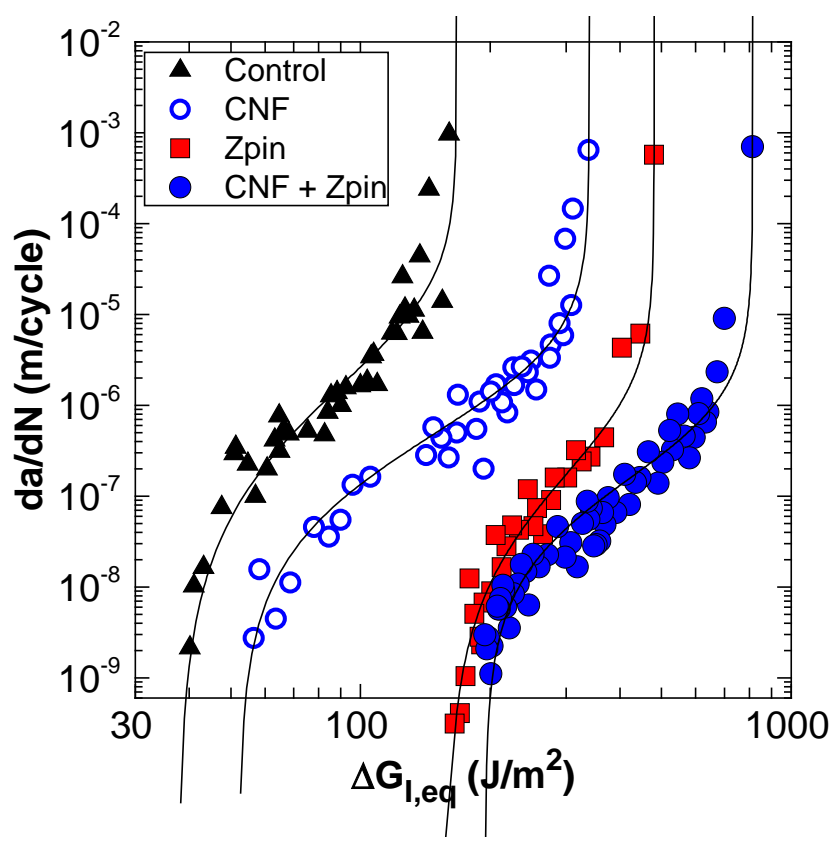

8 Fig. 9 Plots showing the values of $d a / d N$ versus $\Delta G_{I, e q}$ for the control laminate and the laminates reinforced 9 with 0.82 vol.\% CNFs and/or 0.5 vol.\% z-pins. 


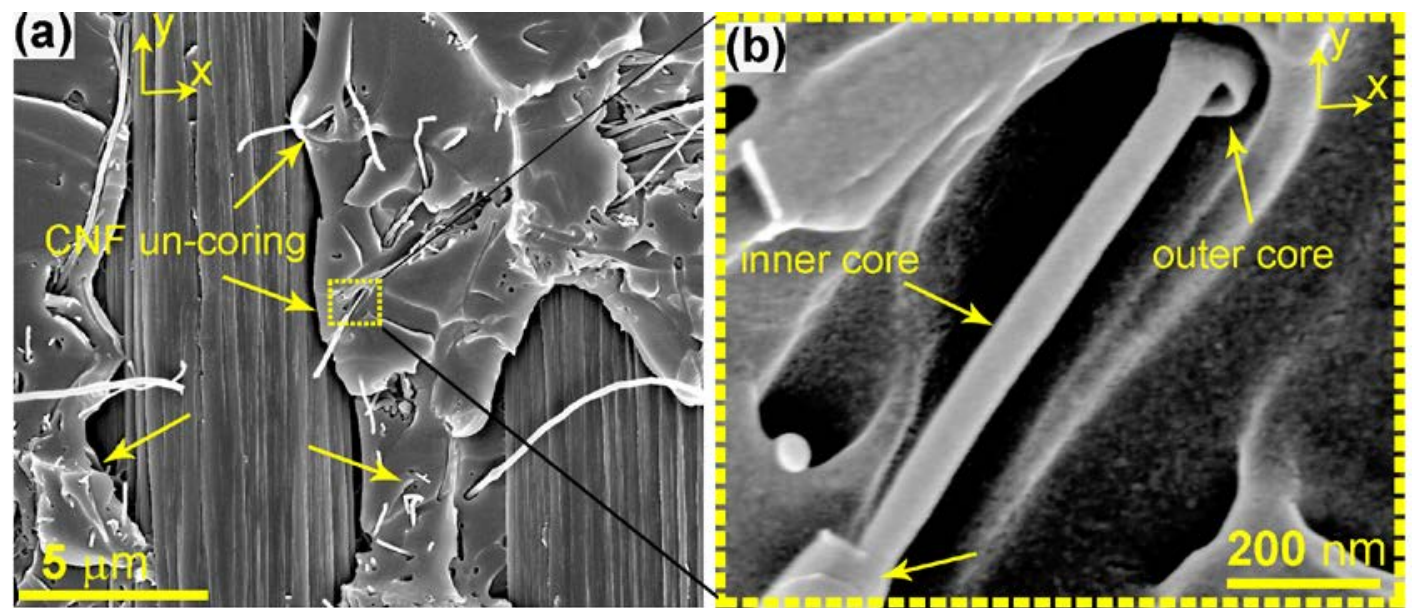

2 Fig. $10 \mathrm{CNF}$ un-coring type damage as observed on the fracture surface of the CNF reinforced laminate 3 tested under fatigue loading. (Note: Please refer to Figure 3 for the DCB z-axis loading direction.) 4 5

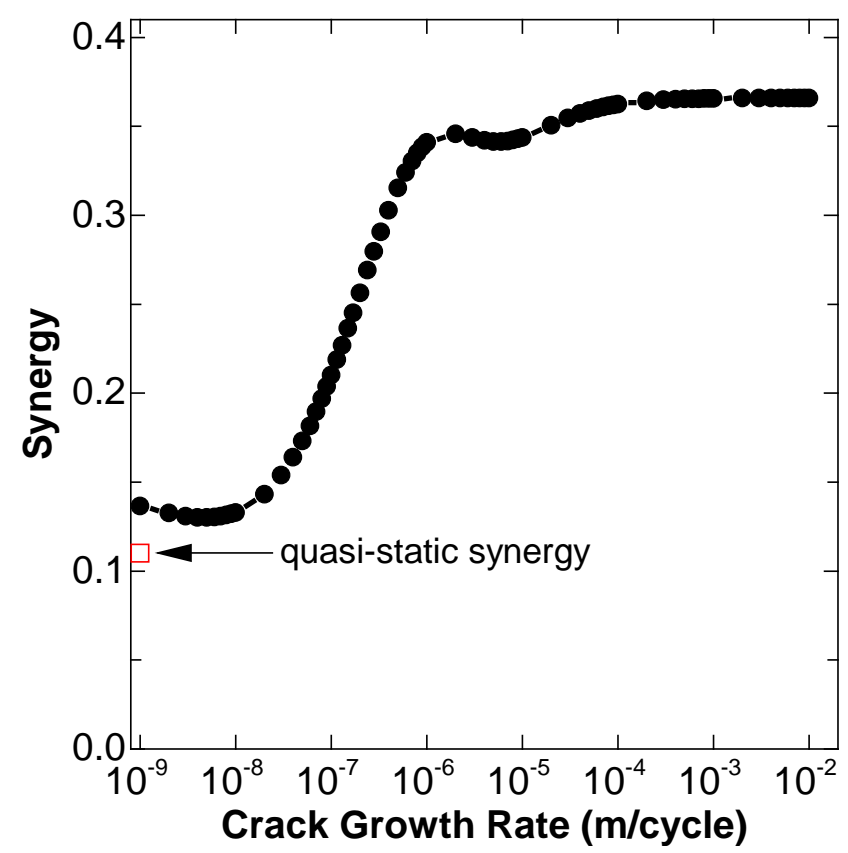

Fig. 11 The level of improvement in the value of $\Delta G_{e q}$, as function of the fatigue crack growth rate, $d a / d N$, 8 for the laminate reinforced with CNFs and z-pins concurrently. 

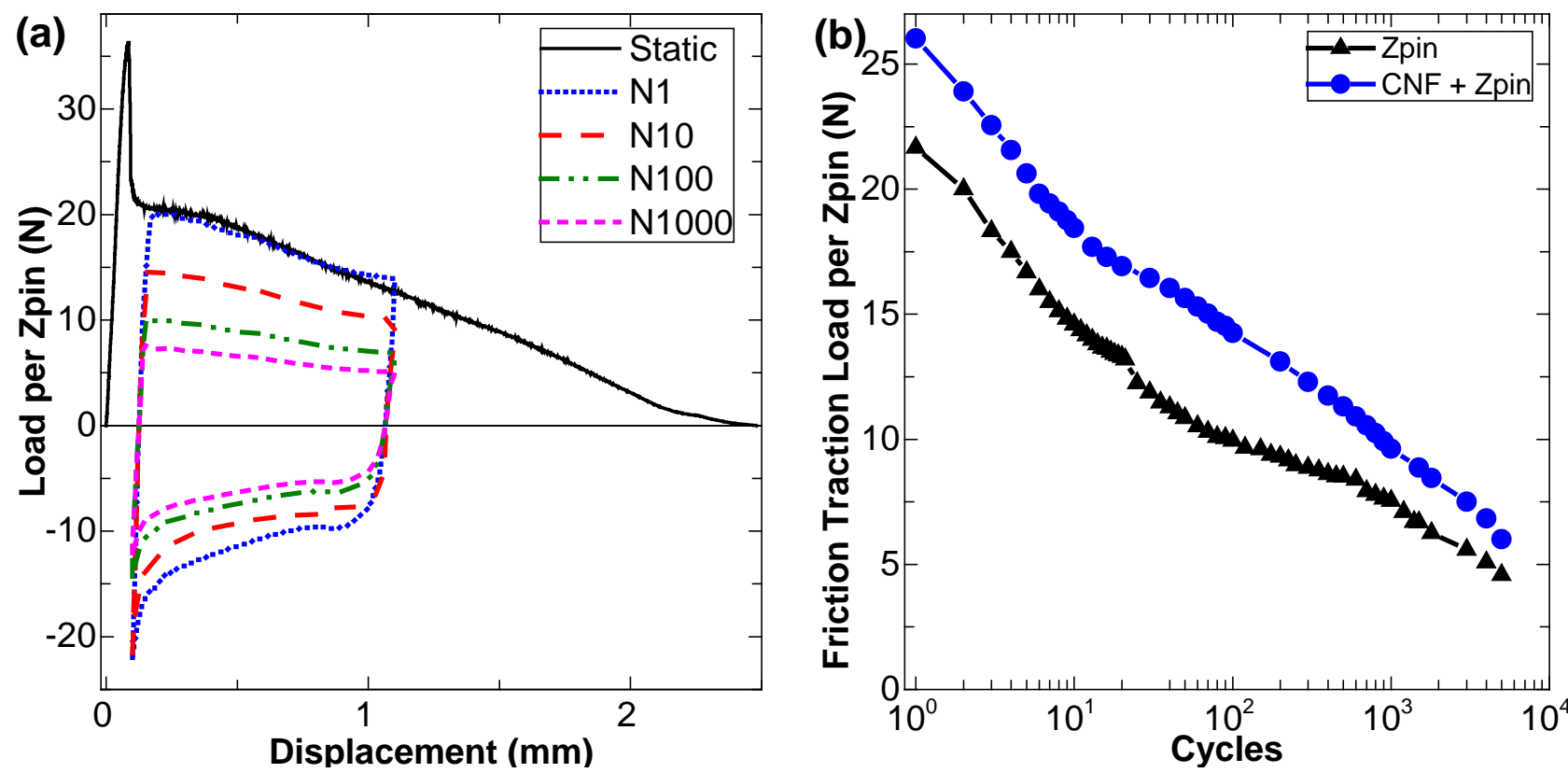

2 Fig. 12 (a) Effect of cyclic loading on the z-pin friction traction load-displacement curve with increasing

3 number of load cycles as measured for the z-pin pull-out specimen reinforced with 0.5 vol.\% of z-pins. $\mathrm{N}$ is

4 the number of load cycles. (b) The peak z-pin friction traction load measured with increasing number of load

5 cycles for the pin pull-out specimen reinforced with z-pins only and the specimen reinforced with CNFs and 6 z-pins concurrently.
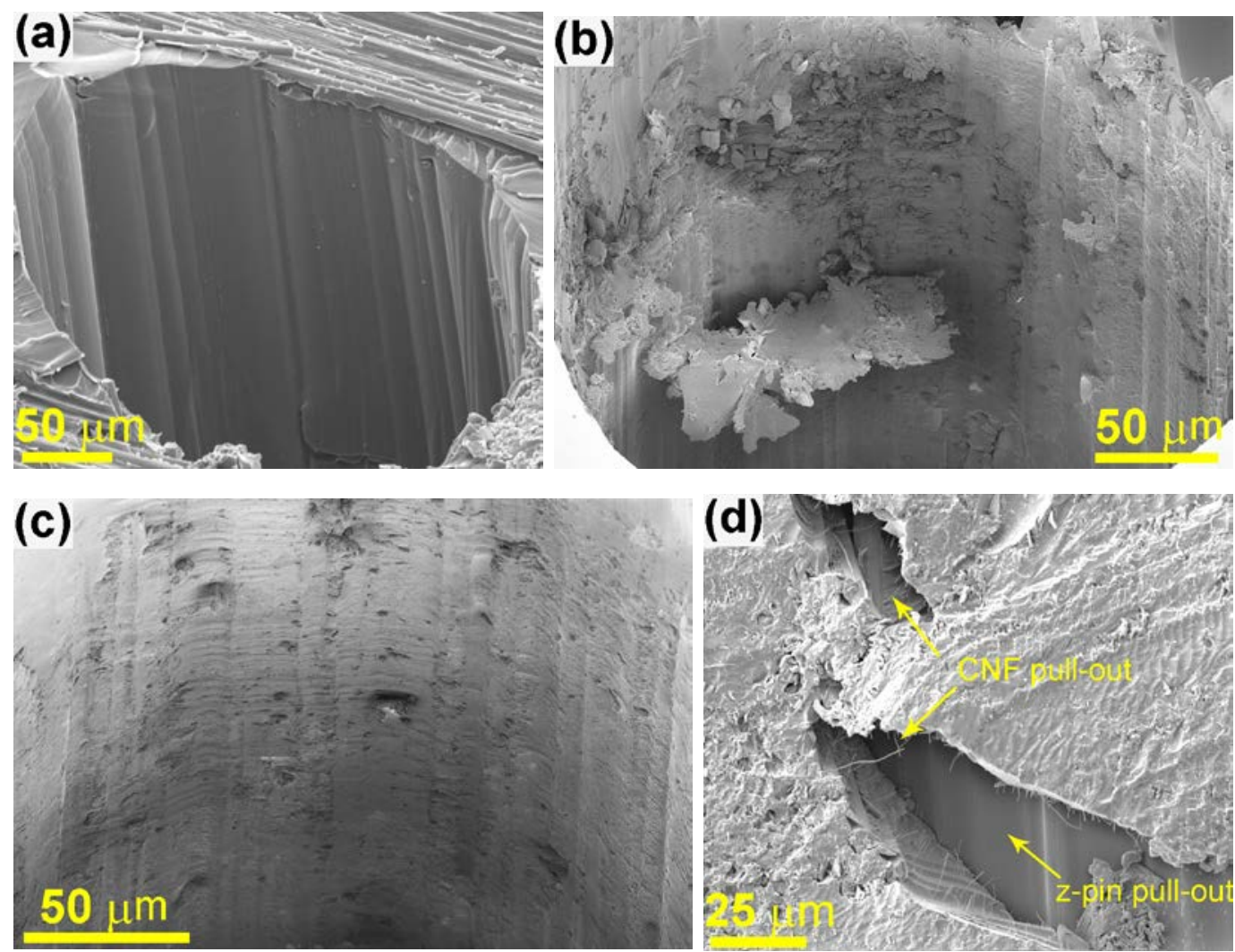

9 Fig. 13 SEM micrographs of the hole walls formed by z-pin pull-out under (a) quasi-static loading and (b)

10 cyclic fatigue loading of specimens with unreinforced matrix; and (c-d) for specimens reinforced with CNFs

11 and tested under fatigue loading. 


\section{References}

[1] Kim JK, Sham ML. Impact and delamination failure of woven-fabric composites. Composites Science and Technology. 2000;60(5):745-761.

[2] Lopresto V, Melito V, Leone C, Caprino G. Effect of stitches on the impact behaviour of graphite/epoxy composites. Composites Science and Technology. 2006;66(2):206-214.

[3] Mouritz AP. Review of z-pinned composite laminates. Composites Part A: Applied Science and Manufacturing. 2007;38(12):2383-2397.

[4] Dransfield K, Baillie C, Mai Y-W. Improving the delamination resistance of CFRP by stitching-a review. Composites Science and Technology. 1994;50(3):305-317.

[5] Mouritz AP, Bannister MK, Falzon PJ, Leong KH. Review of applications for advanced threedimensional fibre textile composites. Composites Part A: Applied Science and Manufacturing. 1999;30(12):1445-1461.

[6] Tang Y, Ye L, Zhang Z, Friedrich K. Interlaminar fracture toughness and CAI strength of fibrereinforced composites with nanoparticles - A review. Composites Science and Technology. 2013;86:26-37.

[7] Wicks SS, Wang W, Williams MR, Wardle BL. Multi-scale interlaminar fracture mechanisms in woven composite laminates reinforced with aligned carbon nanotubes. Composites Science and Technology. 2014;100:128-135.

[8] Khan SU, Kim JK. Improved interlaminar shear properties of multiscale carbon fiber composites with bucky paper interleaves made from carbon nanofibers. Carbon. 2012;50(14):5265-5277.

[9] Zhang J, Yang T, Lin T, Wang CH. Phase morphology of nanofibre interlayers: Critical factor for toughening carbon/epoxy composites. Composites Science and Technology. 2012;72(2):256-262.

[10] Mouritz AP, Cox BN. A mechanistic interpretation of the comparative in-plane mechanical properties of 3D woven, stitched and pinned composites. Composites Part A: Applied Science and Manufacturing. 2010;41(6):709-728.

[11] Mouritz AP, Chang P. Tension fatigue of fibre-dominated and matrix-dominated laminates reinforced with z-pins. Int J Fatigue. 2010;32(4):650-658.

[12] Lubineau G, Rahaman A. A review of strategies for improving the degradation properties of laminated continuous-fiber/epoxy composites with carbon-based nanoreinforcements. Carbon. 2012;50(7):2377-2395.

[13] Veedu VP, Cao AY, Li XS, Ma KG, Soldano C, Kar S, et al. Multifunctional composites using reinforced laminae with carbon-nanotube forests. Nat Mater. 2006;5(6):457-462.

[14] Zhang Q, Liu J, Sager R, Dai L, Baur J. Hierarchical composites of carbon nanotubes on carbon fiber: Influence of growth condition on fiber tensile properties. Composites Science and Technology. 2009;69(5):594-601.

[15] Wang RZ, Gupta HS. Deformation and fracture mechanisms of bone and nacre. Annu Rev Mater Res. 2011;41:41-73.

[16] Studart AR. Towards high-performance bioinspired composites. Adv Mater. 2012;24(37):5024-5044.

[17] Li L, Ortiz C. A natural 3D interconnected laminated composite with enhanced damage resistance. Adv Funct Mater. 2015;25(23):3463-3471. 
[19] Wegst UGK, Bai H, Saiz E, Tomsia AP, Ritchie RO. Bioinspired structural materials. Nat Mater. 2014;14(1):23-36.

3 [20] Launey ME, Buehler MJ, Ritchie RO. On the mechanistic origins of toughness in bone. Annual 4 Review of Materials Research, vol. 402010. p. 25-53.

5 [21] Ritchie RO. The conflicts between strength and toughness. Nat Mater. 2011;10(11):817-822.

[22] Wu S, Ladani RB, Zhang J, Kinloch AJ, Zhao Z, Ma J, et al. Epoxy nanocomposites containing magnetite-carbon nanofibers aligned using a weak magnetic field. Polymer (United Kingdom). 2015;68:2534.

[23] Bortz DR, Merino C, Martin-Gullon I. Carbon nanofibers enhance the fracture toughness and fatigue performance of a structural epoxy system. Composites Science and Technology. 2011;71(1):31-38.

[24] Ladani RB, Wu S, Kinloch AJ, Ghorbani K, Zhang J, Mouritz AP, et al. Improving the toughness and electrical conductivity of epoxy nanocomposites by using aligned carbon nanofibres. Composites Science and Technology. 2015;117:146-158.

[25] Fiedler B, Gojny FH, Wichmann MHG, Nolte MCM, Schulte K. Fundamental aspects of nanoreinforced composites. Composites Science and Technology. 2006;66(16):3115-3125.

[26] Hsieh TH, Kinloch AJ, Taylor AC, Kinloch IA. The effect of carbon nanotubes on the fracture toughness and fatigue performance of a thermosetting epoxy polymer. J Mater Sci. 2011;46(23):7525-7535.

[27] Wu S, Ladani RB, Zhang J, Bafekrpour E, Ghorbani K, Mouritz AP, et al. Aligning multilayer graphene flakes with an external electric field to improve multifunctional properties of epoxy nanocomposites. Carbon. 2015;94:607-618.

[28] Ladani RB, Wu S, Kinloch AJ, Ghorbani K, Zhang J, Mouritz AP, et al. Multifunctional properties of epoxy nanocomposites reinforced by aligned nanoscale carbon. Mater Design. 2016;94:554-564.

[29] Wagner HD, Ajayan PM, Schulte K. Nanocomposite toughness from a pull-out mechanism. Composites Science and Technology. 2013;83:27-31.

[30] Wichmann MHG, Schulte K, Wagner HD. On nanocomposite toughness. Composites Science and Technology. 2008;68(1):329-331.

[31] Koester KJ, Ager Iii JW, Ritchie RO. The true toughness of human cortical bone measured with realistically short cracks. Nat Mater. 2008;7(8):672-677.

[32] Pingkarawat K, Mouritz AP. Improving the mode I delamination fatigue resistance of composites using z-pins. Composites Science and Technology. 2014;92:70-76.

[33] Pegorin F, Pingkarawat K, Mouritz AP. Comparative study of the mode I and mode II delamination fatigue properties of z-pinned aircraft composites. Materials and Design. 2015;65:139-146.

[34] Westsystem. 105 Resin Engineering Data http://www.westsystem.com/ss/assets/Product-DataPDFs/TDS 105_206.pdf. 2015.

[35] Sadeghian R, Gangireddy S, Minaie B, Hsiao KT. Manufacturing carbon nanofibers toughened polyester/glass fiber composites using vacuum assisted resin transfer molding for enhancing the mode-I delamination resistance. Composites Part A: Applied Science and Manufacturing. 2006;37(10):1787-1795.

[36] Mouritz AP, Chang P, Isa MD. Z-pin composites: Aerospace structural design considerations. Journal of Aerospace Engineering. 2011;24(4):425-432. 
[37] ASTM-D5528-01. Standard test method for mode I interlaminar fracture toughness of unidirectional

2 fiber-reinforced polymer matrix composites. ASTM International; 2007.

3 [38] ASTM-D3039-14. Standard test method for tensile properties of polymer matrix composite materials.

4 ASTM International; 2014.

[39] Zhang AY, Liu HY, Mouritz AP, Mai YW. Experimental study and computer simulation on degradation of z-pin reinforcement under cyclic fatigue. Composites Part A: Applied Science and Manufacturing. 2008;39(2):406-414.

[40] Donough MJ, Gunnion AJ, Orifici AC, Wang CH. Plasticity induced crack closure in adhesively bonded joints under fatigue loading. International Journal of Fatigue. 2015;70:440-450.

[41] Ladani RB, Ravindran AR, Wu S, Pingkarawat K, Kinloch AJ, Mouritz AP, et al. Multi-scale toughening of fibre composites using carbon nanofibres and z-pins. Composites Science and Technology. 2016:Submitted.

[42] Wang CH. On the fracture of constrained layers. International Journal of Fracture. 1998;93(1-4):227246.

[43] Forman RG, Kearney VE, Engle RM. Numerical analysis of crack propagation in cyclic-loaded structures. J Basic Eng-T Asme. 1967;89(3):459-463.

[44] Park JM, Wang ZJ, Jang JH, Gnidakoung JRN, Lee WI, Park JK, et al. Interfacial and hydrophobic evaluation of glass fiber/CNT-epoxy nanocomposites using electro-micromechanical technique and wettability test. Composites Part A: Applied Science and Manufacturing. 2009;40(11):1722-1731.

[45] Pedrazzoli D, Pegoretti A, Kalaitzidou K. Synergistic effect of exfoliated graphite nanoplatelets and short glass fiber on the mechanical and interfacial properties of epoxy composites. Composites Science and Technology. 2014;98:15-21.

[46] Palmeri MJ, Putz KW, Ramanathan T, Brinson LC. Multi-scale reinforcement of CFRPs using carbon nanofibers. Composites Science and Technology. 2011;71(2):79-86.

[47] Mouritz AP, Koh TM. Re-evaluation of mode i bridging traction modelling for z-pinned laminates based on experimental analysis. Composites Part B: Engineering. 2014;56:797-807.

[48] Kim JK, Mai Yw. High strength, high fracture toughness fibre composites with interface control-A review. Composites Science and Technology. 1991;41(4):333-378.

[49] Donough MJ, Gunnion AJ, Orifici AC, Wang CH. Scaling Parameter for Fatigue Delamination Growth in Composites under Varying Load Ratios. Composites Science and Technology. 2015;120(4):39-48.

[50] Rans C, Alderliesten R, Benedictus R. Misinterpreting the results: How similitude can improve our understanding of fatigue delamination growth. Composites Science and Technology. 2011;71(2):230-238. 